\title{
Changes in left ventricular stroke volume measured by Doppler echocardiography
}

\author{
HALFDAN IHLEN, ERIK MYHRE, JAN P AMLIE, KOLBJØRN FORFANG, \\ STIG LARSEN \\ From the Medical Department B, Rikshospitalet, University Hospital, Oslo, Norway
}

SUMMARY Cardiac stroke volume was measured simultaneously by Doppler echocardiography and thermodilution in 20 patients with coronary artery disease. Stroke volume as determined by ultrasound was calculated from the area of the aortic orifice and the flow velocity just distal to the aortic cusps. The recordings were made twice at rest. Ten patients were given dobutamine (2.5 and $5.0 \mu \mathrm{g} / \mathrm{kg} / \mathrm{min}$ ) by infusion to induce rapid changes in stroke volume from the resting state. The individual Doppler data before, during, and after dobutamine infusion correlated closely with the thermodilution data $(r=0.92)$. These results suggest that Doppler echocardiography reliably detects changes in stroke volume.

Several groups have reported successful estimation of cardiac output by different methods of Doppler echocardiography. ${ }^{1-3}$ We have described a method which measures flow at the aortic orifice. ${ }^{4}$ Repeat measurements are simple to obtain and the flow velocities are reproducible. ${ }^{56}$ Doppler echocardiography should be suitable for evaluating rapid changes in cardiac output. We determined whether our method is suitable for measuring changes in stroke volume during dobutamine infusion.

\section{Patients and methods}

Determination of volumetric blood flow by Doppler echocardiography requires a flat velocity profile at the site at which cross sectional area is being measured. ${ }^{7}$ In the human ascending aorta, a flat velocity profile is most likely to be present at the aortic orifice, since at this site blood is accelerated from the wide left ventricle through a small orifice, producing an "inlet" condition. ${ }^{8-10}$. The cross sectional area at the aortic root is considerably larger and during systole is partly occupied by the open aortic valve leaflets. This produces irregular flow patterns in the sinuses of Valsalva ${ }^{1.1}$ and the velocity profile is there-

Requests for reprints to Dr Halfdan Ihlen, Medical Department B, Rikshospitalet, Oslo 1, Norway.

Accepted for publication 7 May 1985 fore not flat over the total cross section of the aortic root. This mathematical and experimental evidence accords with our previous work which showed that when the area of aortic orifice is used flow is accurately predicted but when the aortic root area is used it is considerably overestimated. ${ }^{4}$ Velocity at the aortic orifice cannot be measured from the suprasternal position because the Doppler signal is disturbed by the valve movements. Since blood moves as a mass from the aortic orifice into the aortic root, the velocities in the central core flow are unchanged for a considerable distance. ${ }^{1213}$ This concept is supported by recent experiments in dogs when centreline velocities were the same at different levels in the ascending aorta. ${ }^{14}$ Ultrasonic stroke volume $\left(\mathrm{SV}_{\mathrm{u}}\right)$ and cardiac output $\left(\mathrm{CO}_{\mathrm{u}}\right)$ may therefore be calculated from the equations: $\mathrm{SV}_{\mathrm{u}}=(\mathrm{D} / 2)^{2} \times \pi \times \mathrm{SVI}$ and $C O_{u}=S V_{u} \times H R$ where $D$ is the diameter of the aortic orifice, SVI is the systolic velocity integral of centre aortic root flow, and HR is the heart rate. In early diastole there is irregular flow with formation of eddies in the aortic root. ${ }^{121315}$ This is partly caused by the pulsatile flow pattern but a slight reversed surge towards the left ventricle, aortic wall compliance, and blood drainage into the coronary arteries also contribute. These early diastolic events can be seen as mainly retrograde velocities. They do not satisfy the requirements of a flat velocity profile and are not included in the flow measurements. Other theoretical prerequisites for this formula have been discussed earlier. ${ }^{4,7}$ 




Fig. 1 Comparison of integral of systolic maximum velocity in the aortic root obtained by spectral analysis of the Doppler signal (Chirp-Z Fourier transform) and by an analogue estimator in 20 consecutive patients with normal valves. The grey scale display of the velocity spectrum was traced by following the outline of its darkest portion. Integration of the velocity curves was stopped at aortic valve closure. An average of 10 consecutive beats was used for the calculation. The line of identity is shown.

\section{STUDY POPULATION}

The study was performed in 20 patients (mean age 54 years, range 40-64) undergoing complete left and right heart catheterisation for evaluation of angina pectoris. All had regular sinus rhythm and were without valvar heart disease or intracardiac shunts. They were not selected according to their suitability for ultrasound examination before inclusion in the study. Informed consent was obtained from each patient.

At the end of routine heart catheterisation a thermodilution catheter (Balltherm Thermal Dilution Catheter, Elecath) was positioned in the pulmonary artery, and the patients were brought to the ultrasound laboratory. Blood velocity in the aortic root was recorded by the Doppler technique, and cardiac output was simultaneously measured by thermodilution. These measurements were repeated after patients had rested for 15 minutes in the supine position. In 10 of the 20 patients an infusion of dobutamine hydrochloride was started at an initial dose of $2.5 \mu \mathrm{g} / \mathrm{kg} / \mathrm{min}$, which was then increased to 5.0 after 15 minutes, and, if this was well tolerated the dose was increased to $10.0 \mu \mathrm{g} / \mathrm{kg} / \mathrm{min}$. The infusion rate was kept constant for 15 minutes before the measurements were repeated and the infusion was stopped. Fifteen minutes later the flow mea- surements were repeated. The aortic orifice diameter was determined by cross sectional echocardiography before the first flow measurement and during the highest dobutamine infusion.

\section{DOPPLER TECHNIQUE}

The Doppler measurements were carried out with a commercial multifrequency (1-10 $\mathrm{MHz}$ ) Doppler instrument (ALFRED, Vingmed) which has been described in detail. ${ }^{4}$ The velocity estimator in this instrument accurately determines the maximum velocity in experimental studies and in the human aorta. ${ }^{1617}$ In our laboratory the integral of the maximum velocity derived from an adequate Doppler signal distal to normal aortic valves ${ }^{4}$ is similar to that obtained from the maximum velocity estimator (Fig. 1). The analogue velocity curves, the amplitude of the Doppler signal, and the integral of the maximum velocity were recorded on an electrocardiograph together with a phonocardiogram (Fig. 2).

The Doppler probe was placed in the suprasternal position and the aortic valve was identified by the pulsed wave technique. The amplitude signal of aortic valve closure was compared with the phonocardiogram and the corresponding high frequency vibration was later used for timing. The sampling volume was then withdrawn until the valve movements disappeared, and the beam direction was adjusted to obtain the highest velocities in the aortic root. The results of automatic integration of the maximum velocity curve were read when the aortic valve closed, and an average of 10 consecutive beats was used for the calculations. All later measurements were done at exactly the same depth and by the same investigator.

\section{ECHOCARDIOGRAPHY}

An Irex III phased array cross sectional instrument was used for the echocardiographic recordings and the aortic diameter was measured by a digitising computer system (CARDIO 80, Kontron). The aortic orifice diameter ${ }^{8}$ was measured in the parasternal long axis view distally in the outflow tract. The echoes of the orifice appear as two bright spots at or just below the level of attachment of the valve cusps (Fig. 3). Measurements were done at the time in the cardiac cycle at which the orifice echoes were most distinctly seen. The cross section was carefully scanned to ensure that the diameter was measured through the midpoint of the lumen and the distances were determined by use of the leading edge to leading edge standard.

\section{THERMODILUTION TECHNIQUE}

Cardiac output was measured by another investigator using the thermodilution technique, and 


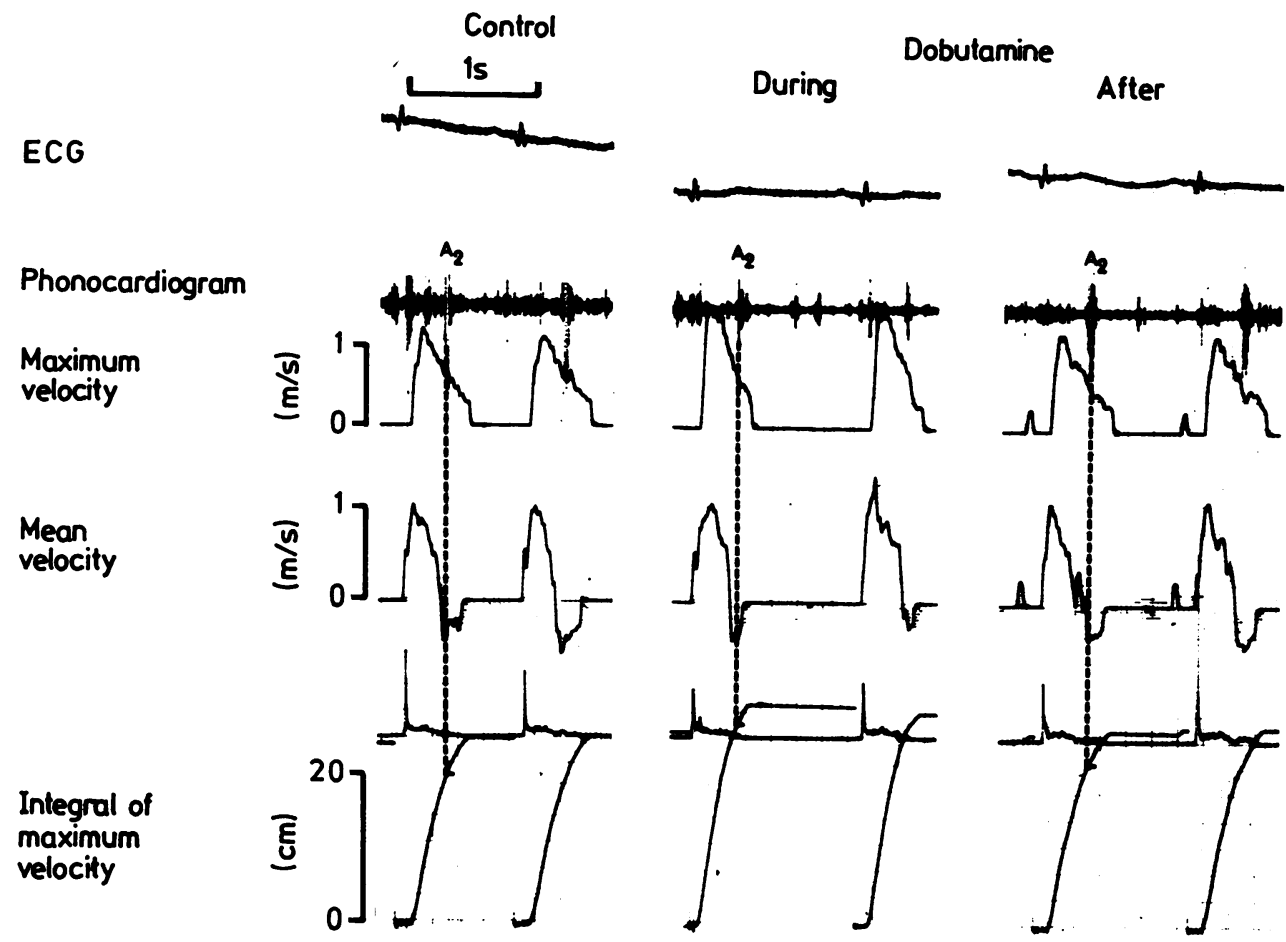

Fig. 2 Electrocardiogram (ECG), phonocardiogram, and analogue signals obtained from the Doppler system during dobutamine infusion. Heart rate fell in parallel with the increase in blood velocity in this patient. Velocities were recorded in early diastole. The maximum velocity estimator is non-directional; the mean velocity estimator shows that these velocities are mainly retrograde. The integral of maximum velocity was read at aortic closure $\left(A_{2}\right)$ and not at the top of the curve.

the results were not compared with those obtained by the Doppler technique until the study was completed. An Elecath Cardiac Output Computer 4000 with digital display was used, and the temperature curve was recorded on a Mingograph 34 electrocardiograph. The output estimate was taken as the mean of three consecutive measurements with identical temperature curves.

\section{STATISTICAL ANALYSIS}

The results were expressed as the median with $95 \%$ confidence interval and changes in the median were tested by means of Wilcoxon's signed mid-rank test. Coefficient of variance and $50 \%$ interquartile range were used as indices of dispersion, ${ }^{18}$ and changes in dispersion were determined by use of Sandvik and Olsson's test. ${ }^{19}$ The results obtained by the thermodilution and Doppler techniques were compared by linear regression analysis.

\section{Results}

STROKE VOLUME IN CONTROL PERIODS

The median of the stroke volume estimates deter-

Table Distribution of estimates of stroke volume ( $\mathrm{ml}$ ) determined by Doppler echocardiography and the thermodilution technique in 20 patients during two control periods (I and II)

\begin{tabular}{|c|c|c|c|c|c|c|}
\hline & \multicolumn{3}{|l|}{ Doppler } & \multicolumn{3}{|c|}{ Thermodilution } \\
\hline & Control I & & Control II & Control I & & Control II \\
\hline $\begin{array}{l}\text { Median (95\% confidence } \\
\text { interval) }\end{array}$ & $\begin{array}{l}85 \\
(68-111)\end{array}$ & NS & $\begin{array}{l}85 \\
(66-105)\end{array}$ & $\begin{array}{l}84 \\
(61-112)\end{array}$ & (NS) & $\begin{array}{l}87 \\
(62-108)\end{array}$ \\
\hline Coefficient of variation & 0.32 & (NS) & $0 \cdot 30$ & $0 \cdot 34$ & (NS) & 0.33 \\
\hline $50 \%$ interquartile range & $60-112$ & (NS) & $60-110$ & $60-121$ & (NS) & $60-109$ \\
\hline
\end{tabular}

NS, not significant. 


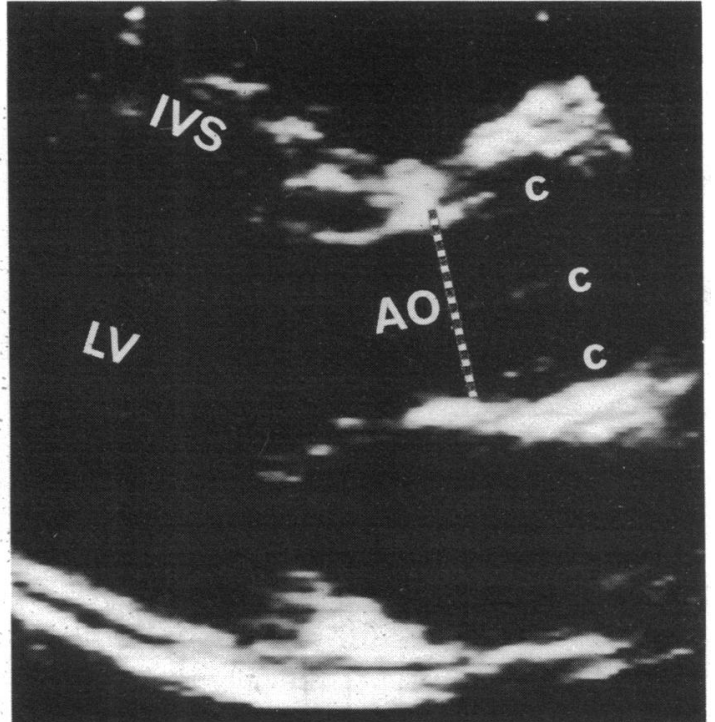

Fig. 3 Cross sectional echocardiogram from the parasternal long axis view showing the aortic valve during systole. The aortic orifice echoes are seen as two bright echoes at the attachment of the right and non-coronary valve cusps. LV, left ventricle; IVS, interventricular septum; $A O$, aortic orifice; $c$, cusps of the aortic valve in the open position.

mined by the Doppler technique was $85 \mathrm{ml}$ during the two control periods. The corresponding medians determined by the thermodilution technique were 84 and $87 \mathrm{ml}$ (Table). There was a similar distribution

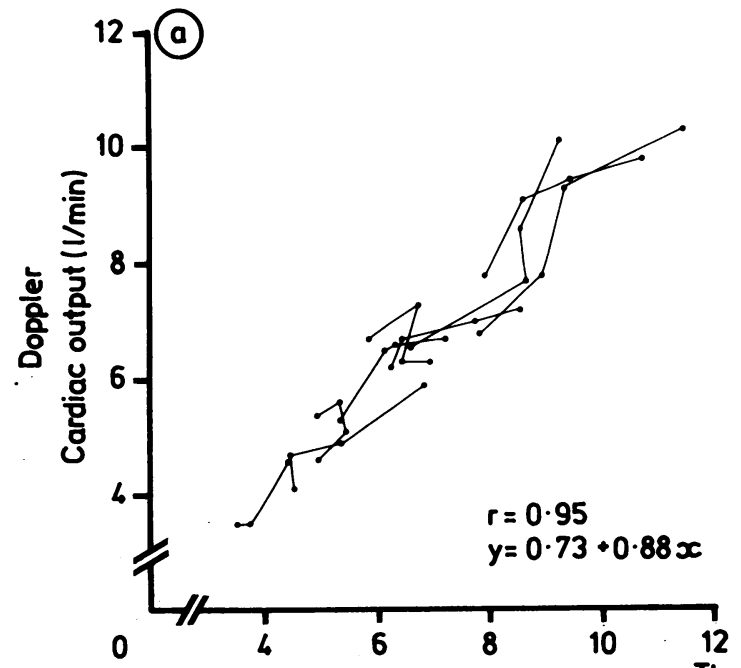

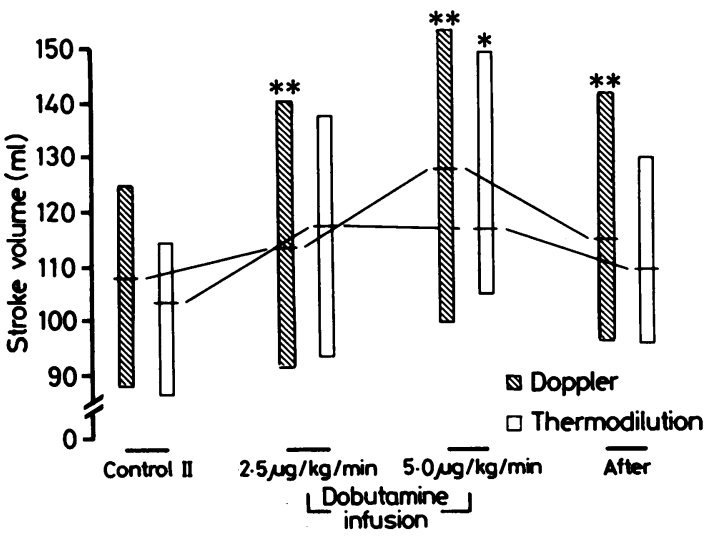

Fig. 4 Estimates of stroke volume (median with 95\% confidence intervals) obtained in 10 patients by Doppler echocardiography and by thermodilution during the second control period (II) and during and after dobutamine infusions. ${ }^{\star} p<0.02 \mathrm{VS}$ control $\mathrm{II} ;{ }^{\star \star} p<0.01 \mathrm{VS}$ control II.

of stroke volume estimates obtained by the Doppler technique in the two control periods which resembled the results when stroke volume was measured by thermodilution. The median of differences between estimates obtained in the two control periods for each patient was $2 \mathrm{ml}$ with both techniques, which was not significantly different from zero.

The results obtained by the Doppler and thermodilution techniques were not significantly different in either of the control periods.

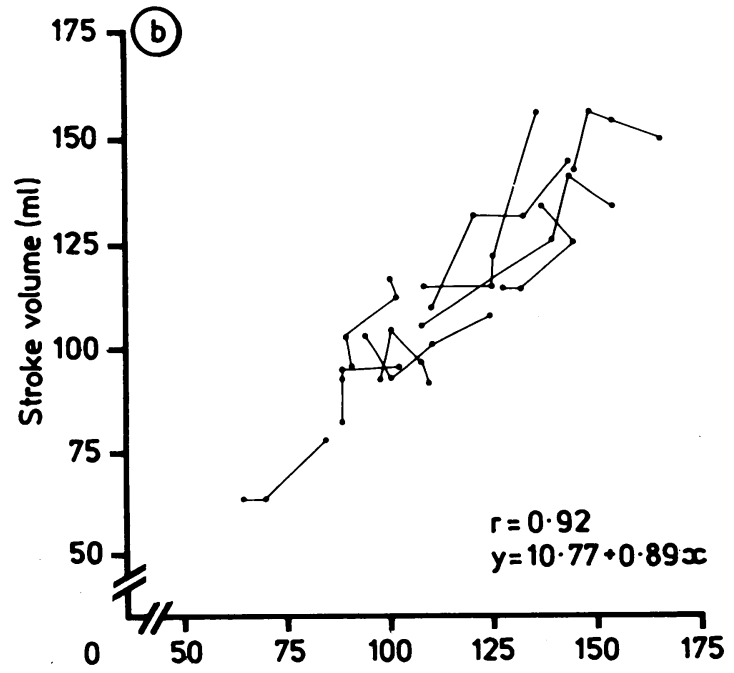

Fig. 5 Individual values of (a) cardiac output and (b) stroke volume obtained by Doppler echocardiography and by thermodilution for 10 patients during the second control period (II), and during and after dobutamine. Results from the same patients are joined by lines. 
CHANGES IN STROKE VOLUME BY DOBUTAMINE INFUSION

The lower dobutamine infusion rate for the 10 treated patients was $2.5 \mu \mathrm{g} / \mathrm{kg} / \mathrm{min}$ and the higher dose was $5.0 \mu \mathrm{g} / \mathrm{kg} / \mathrm{min}$. In one patient, drug infusion at the dose of $5.0 \mu \mathrm{g} / \mathrm{kg} / \mathrm{min}$ was stopped because of chest pain before measurements were performed. No other complications were observed.

Dobutamine at an infusion rate of $2.5 \mu \mathrm{g} / \mathrm{kg} / \mathrm{min}$ increased stroke volume estimates (Fig. 4) obtained with Doppler echocardiography by $14 \%(\mathrm{p}<0.01)$, whereas the increase in stroke volume determined by the thermodilution technique was $5 \%$; this increase was not statistically significant. Infusion of dobutamine at the higher rate produced changes in stroke volume which were significantly higher than control values by both techniques-14\% $(p<0.01)$ and $19 \%(p<0.02)$ for the Doppler and thermodilution techniques respectively. Fifteen minutes after the infusion, stroke volume was not significantly different from that during the control periods.

There was no significant difference in stroke volumes determined by the two techniques either during or after the dobutamine infusions. For the 10 patients from the second control period and during and after the dobutamine infusions, individual Doppler data correlated closely $(r=0.92, p<0.001)$ with the results obtained by thermodilution technique (Fig. 5). Dobutamine did not change the heart rate significantly and Fig. 5 shows that alterations in cardiac output were the result of altered stroke volume.

\section{Discussion}

We obtained blood flow measurements in the present study at the aortic orifice, where the velocity profile is probably flat. ${ }^{1012}$ In an earlier study we found that flow measurements in that area were reliable ${ }^{4}$ whereas the successful flow measurements in the aortic root reported by others ${ }^{23}$ were not confirmed. Experiments in dogs showed a flat velocity profile during baseline conditions, but much higher velocities in the central core flow in the ascending aorta during isoprenaline infusion..$^{20}$ If this is true in man, measurement of flow in the aortic root by ultrasound might be unreliable during catecholamine stimulation and possibly during physical exercise. On the other hand, our Doppler technique for determination of cardiac output requires a flat velocity profile in the aortic orifice not in the aortic root. We presume that the highest velocity of central core flow in the aortic root equals the aortic orifice velocity. 1213

Another feature of our method is that blood vel- ocity is determined by a frequency estimator without use of the zero crossing technique. Obviously, spectral analysis of velocities in normal flow patterns is not needed for reliable results. This is because of the good signal to noise ratio which generally obtains during Doppler measurements in the aortic root distal to a normal valve. The frequency estimator which automatically integrates the maximum velocity is more convenient for clinical work than spectral analysis for which manual integration is required. Combined display of velocity spectrum and the analogue curve is preferable, but was not possible at the time of the study. A third characteristic of our method is that only systolic blood flow is recorded. Measurement of blood flow during early diastole is impossible because of an irregular flow pattern. ${ }^{121315}$ Reverse flow in early diastole is probably of minor importance; other difficulties in the calculation of flow from Doppler echocardiography are more important. ${ }^{4} 7$

We determined whether the ultrasound technique could detect changes in stroke volume; these might be more important clinically than an exact volumetric measurement. In a recent study the reproducibility of aortic root velocities by the Doppler technique was reported to be acceptable, ${ }^{6}$ and the technique might therefore be suitable for the evaluation of changes in flow. We only determined intraobserver variability during two control periods 15 minutes apart because we were attempting to determine changes in stroke volume. The results showed that the variability of our Doppler method was acceptable for this purpose.

The Doppler instrument measures flow velocities over a single heart cycle and therefore estimates the beat to beat stroke volume. ${ }^{21}$ Thermodilution, on the other hand, measures flow during a certain time independent of heart rate, and stroke volume is calculated as an average of several heart beats. To compare stroke volume calculated by the two methods, dobutamine was infused intravenously in doses which did not change the heart rate significantly. By keeping heart rate constant, we were able to show that the Doppler technique may be used to detect volumetric changes in flow. The change in stroke volume induced by dobutamine was small; higher doses would probably alter flow further by increasing the heart rate. Patients with heart failure, in whom haemodynamic monitoring is of particular interest, were not included in this study. Because changes in flow during and after dobutamine were apparently unrelated to the magnitude of baseline stroke volume we believe that the method will detect stroke volume changes in heart failure.

Several haemodynamic variables may be assessed by the Doppler technique which evaluates changes 
in blood flow. Changes in peak blood velocity correlate well with changes in stroke volume except at high flow values. ${ }^{223}$ High stroke volumes are primarily increased by extending the ejection time, which also correlates with stroke volume. ${ }^{22} 24$ The integral of the flow velocity curve includes both of these haemodynamic variables in addition to the early systolic acceleration and the velocity curve form. Thus the flow velocity integral is probably the best estimate of changes in blood velocity and we therefore used this in our study.

Changes in volumetric flow can be calculated from an accurate measurement of cross sectional area. Determination of the aortic area is the factor that is most likely to introduce the largest error into a calculation of cardiac output. This factor is most critical if aortic cross sectional area is altered during systole when cardiac output changes. We have already shown that echocardiographic measurements of the diameter of the aortic orifice are highly reproducible. ${ }^{4}$ Such measurements are unchanged by systole and are also constant when the heart is under the influence of a positive inotropic drug. This implies that changes in aortic flow are caused exclusively by altered blood velocity, and that a single measurement of the area is probably sufficient when changes in cardiac output are being monitored during drug intervention.

In conclusion, Doppler echocardiography reliably measures changes in cardiac stroke volume during and after dobutamine infusion and therefore may be useful for monitoring changes in cardiac output.

\section{References}

1 Sequeira RF, Light LH, Cross G, Raftery EB. Transcutaneous aortovelography. A quantitative evaluation. Br Heart f 1976; 38: 443-50.

2 Goldberg SJ, Sahn DJ, Allen HD, Valdes-Cruz LM, Hoenecke H, Carnahan Y. Evaluation of pulmonary and systemic blood flow by 2-dimensional Doppler echocardiography using fast Fourier transform spectral analysis. Am f Cardiol 1982; 50: 1394-400.

3 Huntsman LL, Stewart DK, Barnes SR, Franklin SB, Colocousis JS, Hessel EA. Noninvasive Doppler determination of cardiac output in man. Clinical validation. Circulation 1983; 67: 593-602.

4 Ihlen H, Amlie JP, Dale J, et al. Determination of cardiac output by Doppler echocardiography. Br Heart f 1984; 51: 54-60.

5 Fraser CB, Light LH, Shinebourne EA, Buchtal A, Healy MJR, Beardshaw JA. Transcutaneous aortovelography: reproducibility in adults and children.
Eur $\mathcal{F}$ Cardiol 1976; 4: 181-9.

6 Gardin JM, Dabestani A, Matin K, Allfie A, Russell D, Henry WL. Reproducibility of Doppler aortic blood flow measurements: studies on intraobserver, interobserver and day-to-day variability in normal subjects. Am f Cardiol 1984; 54: 1092-8.

7 Schuster AH, Nanda NC. Doppler echocardiographic measurement of cardiac output: comparison with a nongolden standard. Am f Cardiol 1984; 53: 257-9.

8 Williams PL, Warwick R, eds. Gray's anatomy. 35th ed. Edinburgh: Longman, 1973: 599-615.

9 McDonald DA. Blood flow in arteries. 2nd ed. Southampton: Edward Arnold, 1974: 71-117.

10 Hatle L, Angelsen B. Doppler ultrasound in cardiology. Philadelphia: Lea and Febiger, 1982: 8-31.

11 Rushmer RF. Cardiovascular dynamics. 4th ed. Philadelphia, London, Toronto: WB Saunders, 1976: 411-45.

12 Wille $S \emptyset$, Walløe L. Pulsatile pressure and flow in arterial stenoses simulated in a mathematical model. $\mathcal{f}$ Biomed Eng 1981; 3: 17-24.

13 Wille SØ. Pulsatile pressure and flow in an arterial aneurism simulated in a mathematical model. $\boldsymbol{f}$ Biomed Eng 1981; 3: 153-8.

14 Fisher DC, Sahn DJ, Friedman MJ, et al. The effect of variations on pulsed Doppler sampling site on calculation of cardiac output: an experimental study in openchest dogs. Circulation 1983; 67: 370-6.

15 Seed WA, Wood NB. Velocity patterns in the aorta. Cardiovasc Res 1971; 5: 319-30.

16 Angelsen BAJ, Brubakk AO. Transcutaneous measurement of blood flow velocity in the human aorta. Cardiovasc Res 1976; 10: 368-79.

17 Brubakk AO, Angelsen BAJ, Hatle L. Diagnosis of valvular heart disease using transcutaneous Doppler ultrasound. Cardiovasc Res 1977; 11: 461-9.

18 Lehmann EL, D'Abrera HJM. Nonparametrics: statistical methods based on ranks. San Francisco: Holden Day, 1975.

19 Sandvik L, Olsson B. A nearly distribution-free test for comparing dispersion in paired samples. Biometrika 1982; 69: 484-7.

20 Falsetti HL, Carroll RJ, Swope RD, Chen CJ. Turbulent blood flow in the ascending aorta of dogs. Cardiovasc Res 1983; 17: 427-36.

21 Loeppky JA, Greene ER, Hoekenga DE, Caprihan A, Luft UC. Beat-by-beat stroke volume assessment by pulsed Doppler in upright and supine exercise. $f \mathrm{Appl}$ Physiol 1981; 50: 1173-82.

22 Colocousis JS, Huntsman LL, Curreri PW. Estimation of stroke volume changes by ultrasonic Doppler. Circulation 1977; 56: 914-7.

23 Elkayam U, Gardin JM, Berkley R, Hughes CA, Henry WL. The use of Doppler flow velocity measurement to assess the hemodynamic response to vasodilators in patients with heart failure. Circulation 1983; 67: 377-83.

24 Weissler AM, Schoenfeld CD. Effect of digitalis on systolic time intervals in heart failure. $\mathrm{Am} \mathcal{F} \mathrm{Med} S \mathrm{Si}$ 1970; 259: 4-20. 